\title{
Multiple Intracranial Meningiomas - A Case Report
}

Nanda Patil ${ }^{1 *}$, Purva Mayekar ${ }^{2}$, Nitesh Nasre ${ }^{2}$

${ }^{1}$ Professor, Department of Pathology, Krishna Institute of Medical Sciences, Karad, Maharashtra, India

${ }^{2}$ Tutor, Department of Pathology, Krishna Institute of Medical Sciences, Karad, Maharashtra, India

DOI: $10.36347 /$ sjams.2020.v08i07.025

| Received: 12.07.2020 | Accepted: 20.07.2020 | Published: 24.07.2020

*Corresponding author: Nanda Patil

Abstract

Meningiomas are benign tumors, accounting for $13-20 \%$ of all primary central nervous systems tumors. Multiple meningiomas are rare and the term is used for more than one meningioma occurring in several intracranial locations without signs of neurofibromatosis. The prognosis of multiple intracranial meningiomas is similar to benign solitary meningioma. We present a rare case of multiple intracranial meningiomas in a 45 years old female patient.

Keywords: Meningiomas, Multiple, Intracranial.

Copyright @ 2020: This is an open-access article distributed under the terms of the Creative Commons Attribution license which permits unrestricted use, distribution, and reproduction in any medium for non-commercial use (NonCommercial, or CC-BY-NC) provided the original author and source are credited.

\section{INTRODUCTION}

Meningiomas are tumors arising from arachnoidal cells accounting for 13- $20 \%$ of all intracranial tumors [1]. The terminology of multiple meningiomas is used when two or more meningiomas occur simultaneously or sequentially in different intracranial locations without signs of neurofibromatosis. The incidence of multiple meningiomas is about 1 to 2 percent of all meningioma cases [2].

\section{CASE Report}

A 45 years old female patient presented with headache, seizures and upper and lower limb weakness. MRI brain revealed multiple meningiomas along right parietal parasagittal region attached to convexity of dura. The lesions were excised and sent for histopathological examination.

\section{Histopathological Examination}

We received 5 globoid grey white firm tissue pieces with attached dura. The largest tissue piece of the tumor was $7.5 \mathrm{~cm}$ in diameter. Cut section of all tumor pieces were grey white and homogenous (Fig. 1, 2).

Microscopic examination of all tumor deposits showed neoplastic spindle shaped cells arranged in whorled pattern. Neoplastic cells showed elongated, flat nuclei without atypia \& scanty cytoplasm. The tumor showed numerous psammoma bodies. All tumor deposits showed similar microscopic grade. Considering the histopathological features, the diagnosis was given as multiple meninigiomas WHO grade I (Fig. 3, 4).

\section{DiSCUSSION}

A widely accepted hypothesis for multiple meningiomas is spread of clones of neoplastic cells through cerebrospinal fluid as well as hematogenous spread [3]. Different etiological factors were considered in the development of meningiomas, one of which is deletion of chromosome 22 in patients with type II neurofibromatosis. The second etiological factor is hormone. Higher frequency of meningiomas is seen in female patients. Progesterone receptors are found in $80 \%$ meningiomas [4]. In our case, the patient was premenopausal female. The most common location of multiple meningiomas are supratentorial convexity and parasagittal area, posterior fossa being the rare site [5]. Similar location was found that is parietal parasagittal region attached to convexity of dura in our patient.

Histopathological examination of multiple meningiomas reveals similar features as in solitary type, however simultaneous occurance of different grade of malignancies is seen in $1 / 3^{\text {rd }}$ of patients [6]. The common histological types in multiple meningiomas are- psammomatous, fibroblastic, meningoepithelial and transitionaltypes [7]. In our case the microscopy revelaedpsammomatous meningiomas grade $\mathrm{I}$ in all the lesions. Clinically differential diagnosis of multiple meningiomas includes intracranial metastases. Radiological examination helps in detecting the location of these tumors. MRI is more helpful than CT to detect the exact site of tumors. Surgey is the treatment of choice for the multiple menigiomas. Surgical excision is 
done in the case of symptomatic meningiomas and asymptomatic meningiomas more than $3 \mathrm{~cm}$ in size [8]. The prognosis of multiple meningiomas is same as for solitary one.

\section{Conclusion}

Multiple meningiomas are rare and are commonly observed in female patients. Clinically they can mimic intracranial metastasis and histopathological examination helps in making differential diagnosis.

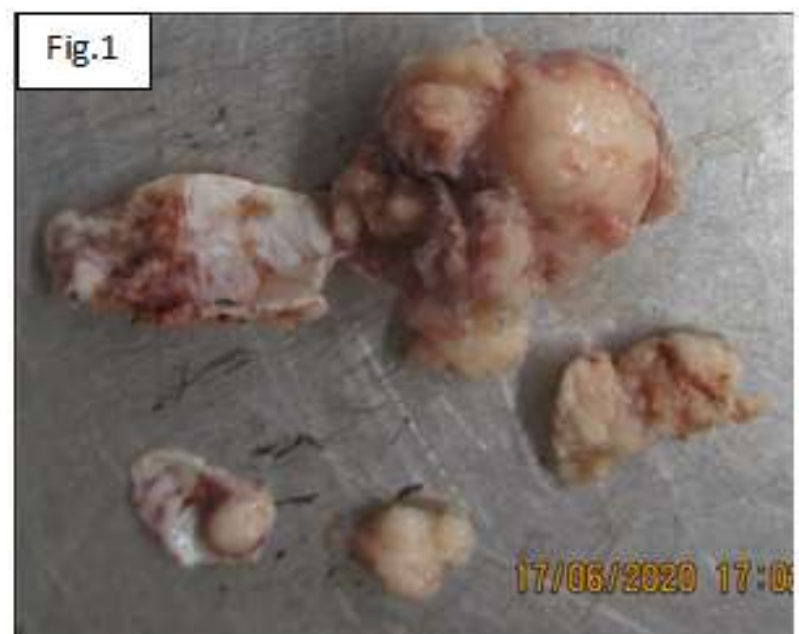

Fig-1: Gross Examination- Multiple globoid grey white pieces of tumor

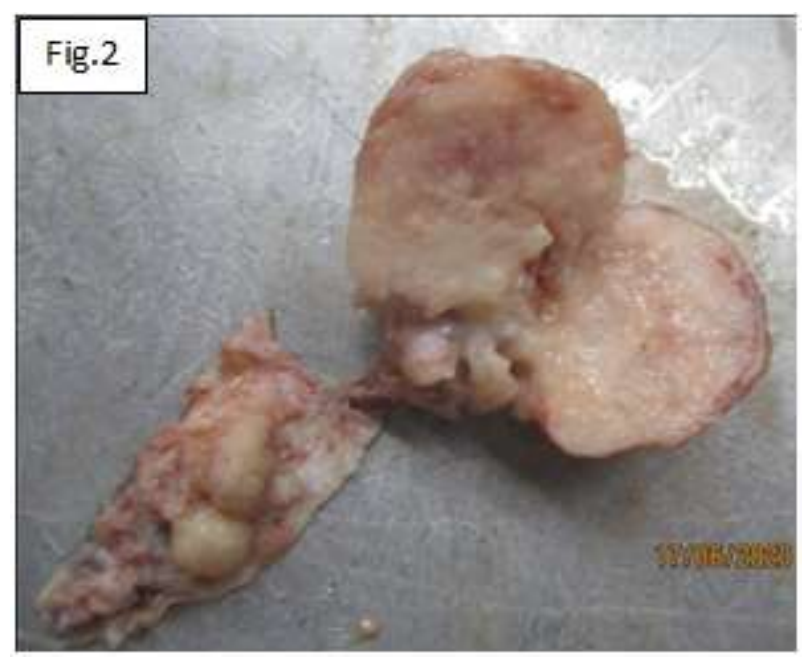

Fig-2: Cut section of tumor was grey white and homogenous

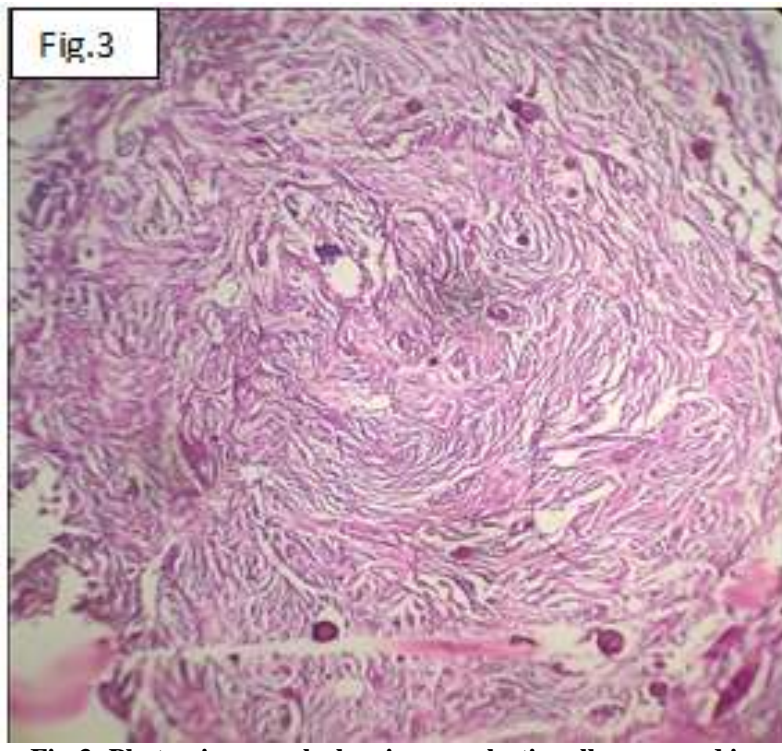

Fig-3: Photomicrograph showing neoplastic cells arranged in whorled pattern $(\mathrm{H} \& \mathrm{E} 100 \mathrm{X})$

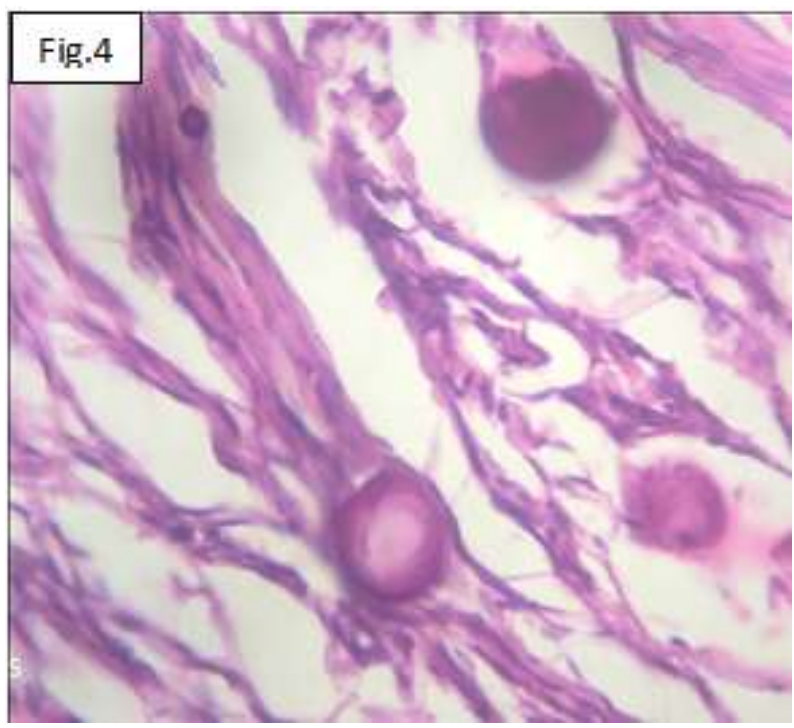

Fig-4: Photomicrograph showing numerous psammoma bodies (H \& E 400X)

\section{REFERENCES}

1. Russel DS, Rubinstein LJ. Pathology of Tumors of the Nervous System. Baltimore, Md, USA: Williams and Wilkins; 1977.

2. Cushing H, Eisenhardt L. Meningiomas: Their Classification, Regional Behaviour, Life History and Surgical End Result. Springfield, Ill, USA: Charles C Thomas; 1938.

3. Yang Liu, Da-Ping Song, Tong Wang, Meningiomas with different histological grade in the same patient, journals.lww.com/md journals. 2017/12150.

4. Gruber T, Dare AO, Balos LL, Lele S, Fenstermaker RA. Multiple Meningiomas arising during long-term therapy with the progesterone agonist megestrol acetate: case report. $\mathrm{J}$ of Neurosurg. 2004; 100(2):328-331. 
5. Kim TS, Park JK, Jung S. Multiple intracranial Meningiomas. J Korean Neurosurg. 1997;26(12):1685-1691.

6. Mocker K, Holland $\mathrm{H}$, Ahnert P. Multiple meningioma with different grades of malignancy: case report with genetic analysis applying single- nucleotide polymorphism array and classical cytogenetics. Pathol Res Pract. 2011;207(1):67-72.

7. Eljamel MSM, Foy PM. Multiple Meningiomas and their relation to neurofibromatosis. Surg Neurol. 1989;32(2):131-136.

8. Sheehy JP, Crockard HA. Multiple Meningiomas: a longterm review. J. Neurosurg. 1983;59(1):1-5. 